\title{
Conversion of Aluminum Phosphate to Sodium
}

\section{Phosphate}

\author{
Masaaki Takahashi ${ }^{1 *}$, Yukimasa Takemoto ${ }^{1}$, Maki Ooyagi ${ }^{1}$, Ken Oonishi $^{2}$ and Eiji Yuuki ${ }^{2}$ \\ 1. Yokkaichi University, Research Laboratory on Environmental Technology, Kayo-cho 1200, Yokkaichi, Mie, 512-8512, Japan \\ 2. Mie Chuo Kaihatsu Co., Ltd, Hachiya4713, Yono, Iga, Mie, 518-1152, Japan
}

\begin{abstract}
The phosphorus recovered from sewage sludge by acidic treatment is mainly composed of aluminum phosphate. To make a wide utilization of recovered phosphorus, removal of the aluminum component is considered a very important matter. In order to find a method to convert aluminum phosphate to sodium phosphate, a basic investigation was carried out. A reagent of aluminum phosphate was dissolved by aqueous solution of sodium hydroxide, and mixed with sodium silicate to make a alunino-silicate gel. Sodium phosphate was recovered from residue water in the gel.
\end{abstract}

Key words: Aluminum phosphate, sodium phosphate, gelation, sodium silicate.

\section{Introduction}

Sewage sludge contains significant amounts of phosphorus, and in order to recover the phosphorus, some studies have been carried out [1-6]. The phosphorus which is recovered by acidic treatment contains a lot of aluminum [7]. To make a wide utilization of recovered phosphorus, the removal of the aluminum component is considered a very important matter, and some methods were investigated [8].

The aluminum component in the recovered phosphorus is considered to exist mainly as a form of aluminum phosphate. Aluminum ion reacts with alkali metal silicate to form a silicate gel, which is widely known as zeolite synthesis. Aluminum phosphate is dissolved by the addition of aqueous solution of alkali metal hydroxide, and is also expected to react with alkali metal silicate to make an alkali metal silicate gel. Using this reaction, alkali metal phosphate is considered to be recovered as reaction (1) [9].

$$
\begin{aligned}
& \mathrm{M}_{2} \mathrm{SiO}_{3}+\mathrm{mAlPO}_{4}+\mathrm{nMOH} \\
& \rightarrow \mathrm{M}_{2} \mathrm{O} \cdot \mathrm{xAl}_{2} \mathrm{O}_{3} \cdot \mathrm{ySiO}_{2} \cdot \mathrm{zH}_{2} \mathrm{O}+\mathrm{M}_{3} \mathrm{PO}_{4}
\end{aligned}
$$

\footnotetext{
*Corresponding author: Masaaki Takahashi, researcher,
} research field: environmental technology. where $\mathrm{M}$ is alkali metal, $\mathrm{m}, \mathrm{n}, \mathrm{x}, \mathrm{y}$ and $\mathrm{z}$ are indefinite numbers.

In order to confirm this method, we investigated the reaction using a reagent of sodium hydroxide, aluminum phosphate and sodium silicate.

\section{Method}

\subsection{Preparation}

In this experiment, sodium hydroxide: Kanto chemical Co., INC (assay minimum 97\%), aluminum phosphate: Kanto chemical Co., INC (assay minimum $95 \%$ as $\mathrm{AlPO}_{4}$ ), sodium silicate: Kanto chemical Co., INC (assay minimum $\mathrm{SiO}_{2}$ : 37\%, $\mathrm{Na}_{2} \mathrm{O}: 18 \%$ ) was used.

Aqueous solutions of these reagents were prepared as mentioned below:

Aq. aluminum phosphate solution: $50 \mathrm{~g}$ of aluminum phosphate was resolved by addition of $50 \mathrm{~g}$ of sodium hydroxide in 1,000 mL of water.

Aq. sodium silicate solution: $100 \mathrm{~g}$ of sodium silicate was in $100 \mathrm{~mL}$ of water (total volume 155 $\mathrm{mL})$.

\subsection{Experimental Procedure}

The experiment was carried out as shown in Fig. 1. 


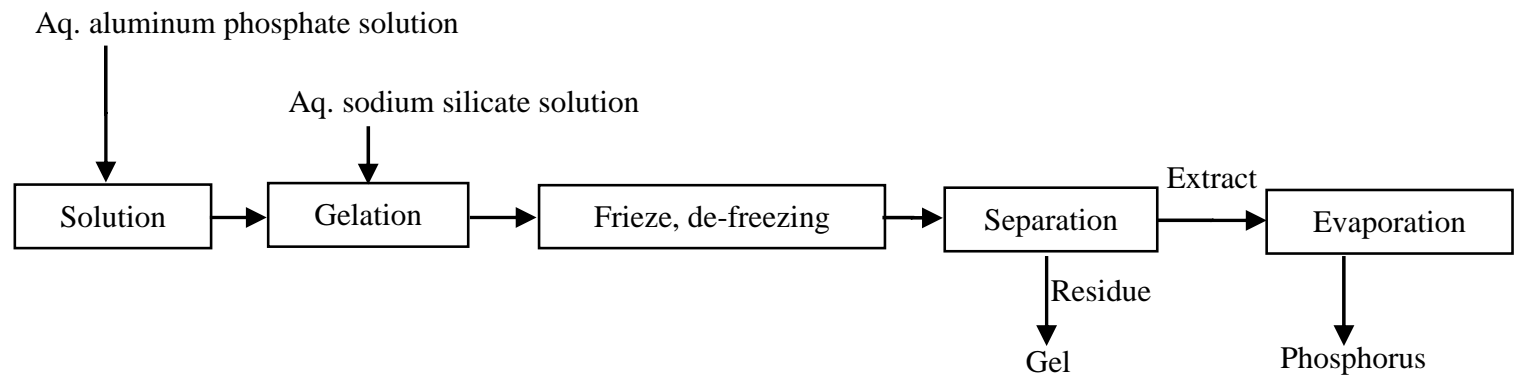

Fig. 1 Experimental procedure.

Aq. sodium silicate solution was added to the aq. solution of aluminum phosphate at room temperature and the mixture formed a transparent gel. In order to estimate the amount of the gel, dehydration is needed. To make rapid dehydration, a freezing and de-freezing method applied to the dehydration of sludge [10], was carried out. The formed gel was cooled in an ice box (under $-10{ }^{\circ} \mathrm{C}$ ) for one day, later, the frozen gel was retained at a room temperature (about $25{ }^{\circ} \mathrm{C}$ ) to make de-freezing. The dehydration was brought about through de-freezing, and the dehydrated gel was separated by filtration, and the residue was dried at $105{ }^{\circ} \mathrm{C}$ for analysis. The phosphorus component was recovered from the extract through evaporation.

\subsection{Addition Rate}

In order to find a proper addition rate, $5 \mathrm{~mL}$ to 20 $\mathrm{mL}$ of aq. sodium silicate solution was added to 100 $\mathrm{mL}$ of aq. aluminum phosphate solution at room temperature (about $25{ }^{\circ} \mathrm{C}$ ), and the mixture formed a gel in a few minutes. The formed gel was cooled in an ice box for 24 hours, and the frozen gel was retained in a room for de-freezing. Dehydration took place through de-freezing, and the dehydrated gel was separated using filter paper (ADVANTEC, No2, Toyo Roshi Co LTD), and residue (gel) was dried at $105^{\circ} \mathrm{C}$ for analysis.

\subsection{Recovery of Phosphorus}

A $200 \mathrm{~mL}$ of aq. aluminum phosphate solution was mixed with a $30 \mathrm{~mL}$ of aq. sodium silicate solution at room temperature, and a gel was formed in a condition of $\mathrm{pH}$ 11.5. The formed gel was cooled in an ice box, and dehydration was carried out as mentioned before. The dehydrated gel was dried and the phosphorus containing extract was evaporated for analysis, and gel (17 g) and phosphorus, (23 g) were recovered.

\section{Result and Discussion}

\subsection{Addition Rate}

The relation of the amount of the formed gel and the addition rate of the sodium silicate is shown in Fig. 2. The amount of the formed gel, increased by addition of sodium silicate, and when the addition rate reached $10 \mathrm{~g}$, amount of the gel tends to plateau. This addition rate is considered to correspond to a molecular ratio $\mathrm{Al}_{2} \mathrm{O}_{3}: \mathrm{SiO}_{2}=0.35: 1$.

\subsection{Properties of Recovered Materials}

The recovered gel is a white powder, particle size: under $0.05 \mathrm{~mm}$ as shown in Fig. 3, bulk density: $0.2 \sim 0.3 \mathrm{~g} / \mathrm{cm}^{3}$. The chemical component of the recovered gel and phosphorus was analyzed by X-ray

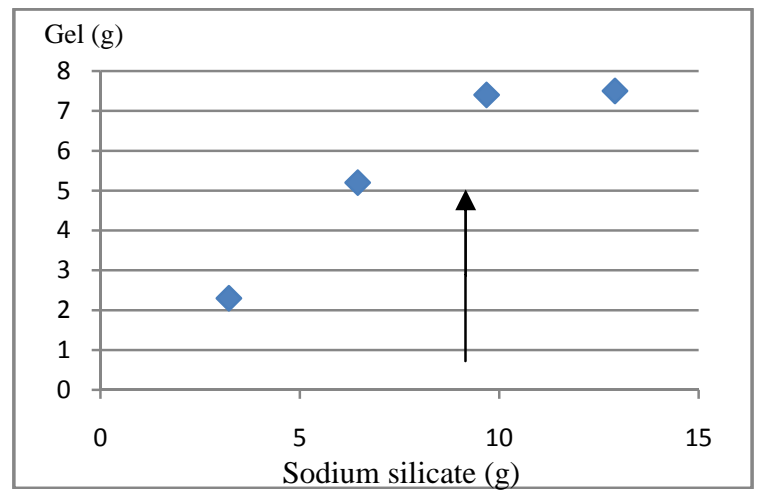

Fig. 2 Relation of sodium silicate and formed gel. 


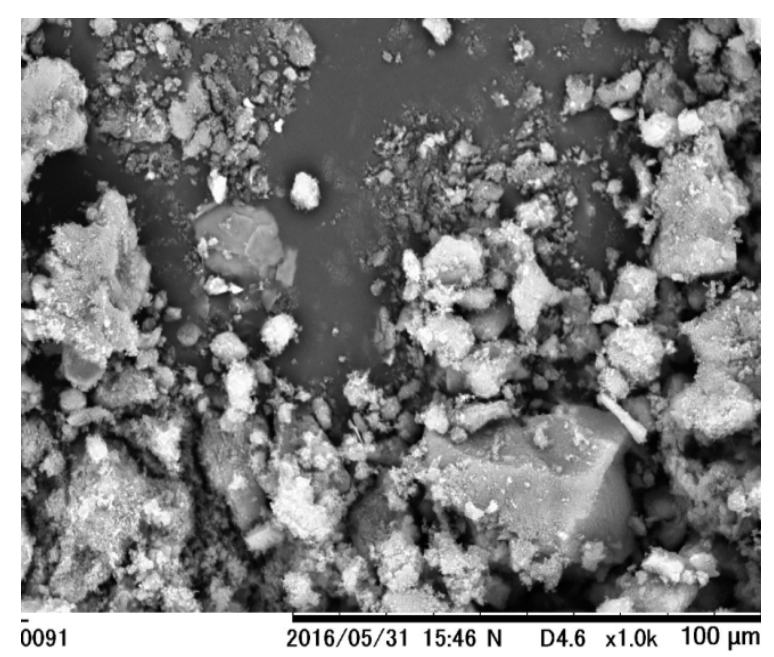

Fig. 3 Photo of the gel.

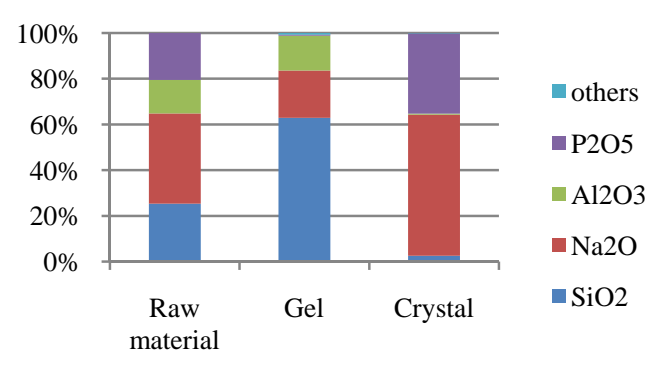

Fig. 4 Chemical composition of recovered materials.

analyzer, (XRF, Rigaku Corporation SPECTRO XEPOS) and the result is shown in Fig. 4. The chemical composition of the raw material was calculated by mass balance of the reagent used in this experiment. The recovered gel was composed of $\mathrm{Na}_{2} \mathrm{O} 、 \mathrm{SiO}_{2} 、 \mathrm{Al}_{2} \mathrm{O}_{3}$, and it was considered to be a compound of alumino- silicate. The elemental ratio of the gel was calculated from the analyzed data and the approximate molecular ratio was considered as (2).

$$
\mathrm{Na}_{2} \mathrm{O} \cdot \mathrm{xAl}_{2} \mathrm{O}_{3} \cdot \mathrm{ySiO}_{2} ; \quad \mathrm{x} / \mathrm{y}=1 / 3
$$

The ratio of $\mathrm{x}: \mathrm{y}$ corresponds to the chemical composition of a zeolite [11]. However, XRD of the gel shows the pattern of an amorphous compound (Fig. 5), and further investigation is needed to identify some properties and physical structure.

The amount of $\mathrm{P}_{2} \mathrm{O}_{5}$ component in the gel is small, and almost of all the phosphorus was separated from the gel as an extract. The recovered phosphorus was composed of $\mathrm{P}_{2} \mathrm{O}_{5}$ and $\mathrm{Na}_{2} \mathrm{O}$, and is considered to be a form of $\mathrm{Na}_{2} \mathrm{HPO}_{4} \cdot 7 \mathrm{H}_{2} \mathrm{O}$ by the XRD analysis (Fig. 6) and recovered condition (pH11-pH12) [12].

A small amount of $\mathrm{SiO}_{2}$ component was found in the recovered phosphorus, which is considered non-reacted sodium silicate which remained in the recovered phosphorus.

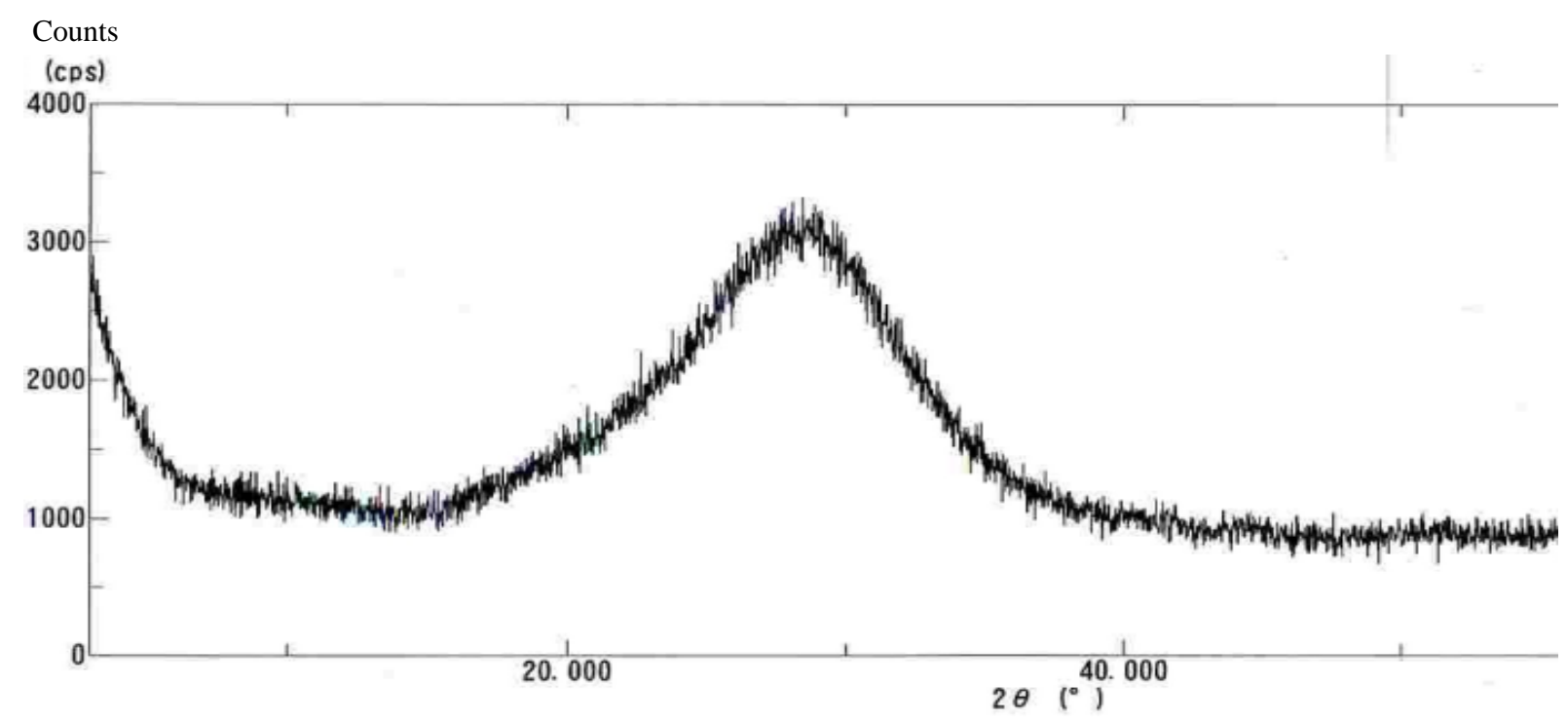

Fig. 5 XRD spectrum of the gel. 


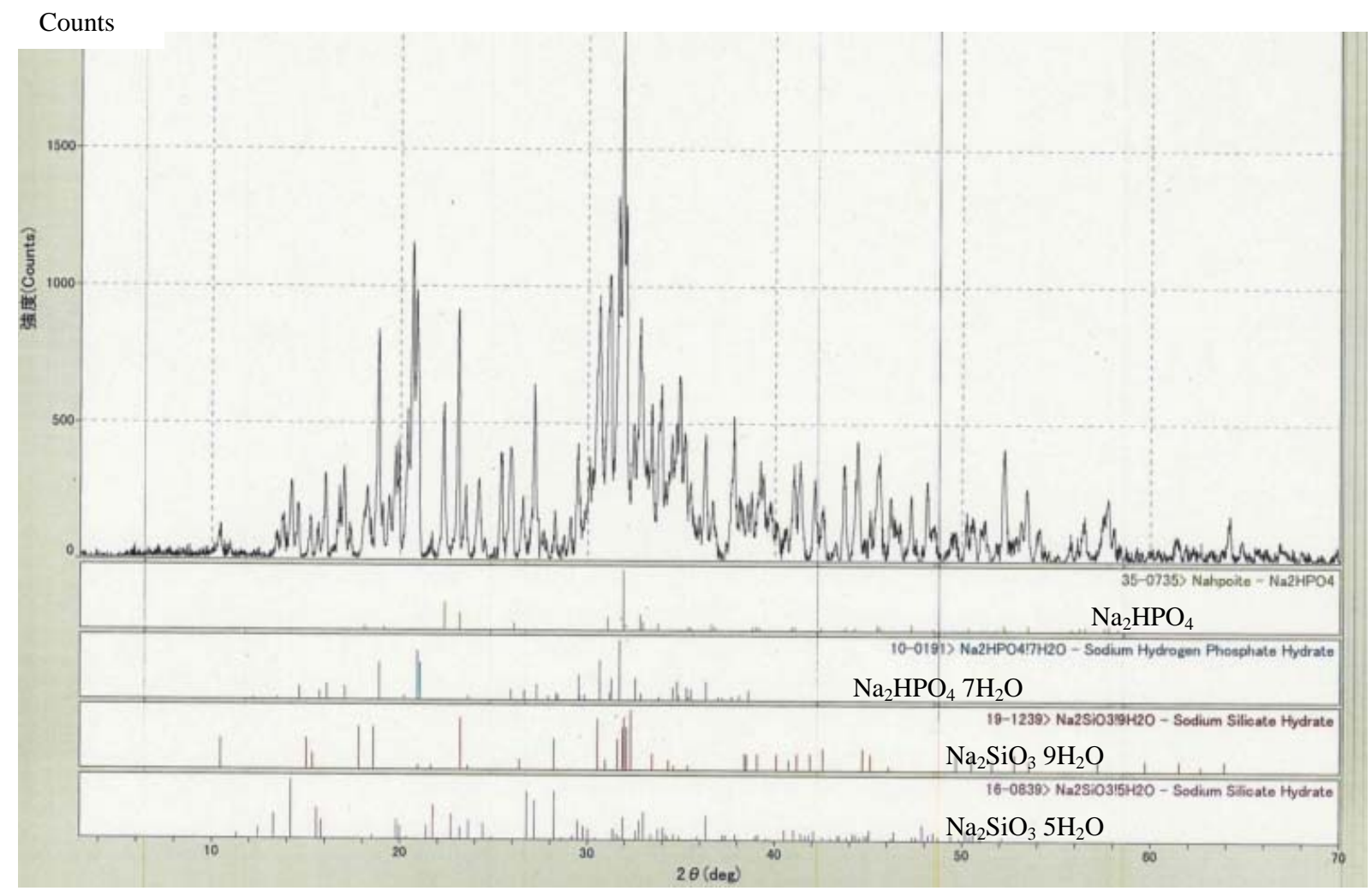

Fig. 6 XRD spectrum of the recovered crystal.

\section{Conclusions}

In order to find a wide utilization of aluminum phosphate which is recovered from sewage sludge, a conversion method of aluminum phosphate to sodium phosphate was investigated using a reagent of aluminum phosphate. Aluminum phosphate which was dissolved by sodium hydroxide reacted with sodium silicate, and formed a silicate gel. Aluminum phosphate was converted to sodium phosphate through the formation of alumino-silicate gel. The result indicates a possibility to make a recovery method of sodium phosphate from sewage sludge. However, further study is needed to investigate the conversion of sodium phosphate from aluminum phosphate which is recovered from sewage sludge.

\section{Reference}

[1] Shima, H. and Takahashi, M. 1997. Gekkan [Mizu] Publishing, Gekkan Water (In Japanese). 39-7 (552): 36-40.

[2] Okano, K., Umemoto, M., Kagami, J., Honda, K.,
Ohtake, H. and Miura, K. et al. 2013. "Novel Technique for Phosphorus Recovery from Aqueous Solutions Using Amorphous Calcium Silicate Hydrates (A-CSHs).” Water Research 47 (7): 2251-9.

[3] Nakahara, K. 2001. "Vitrification Process for Recovery of Phosphorus/Phosphoric Acid from Sewage Sludge Ash.” Industrial Water 514: 2-10.

[4] Sonoda, K., Tokukura, K., Mori, T., Komazawa, I. and Wada, T. 1996. "Phosphoric Acid Recovering from Incinerated Ashes of Sewage Treatment Sludge." In Proceedings of the 7th Annual Conference of the Japan Society of Waste Management Expert, 267-9.

[5] Ingham, J., Ryan, J., Keyakida, E. and Ri, J. 1996. "Phosphorus and Metal Recovery from Sewage Treatment Sludge." In Proceedings of the 7th Annual Conference of the Japan Society of Waste Management Expert, 280-2.

[6] Yoshida, K., Takahashi, Y. and Hatano, M. 2001. “The Experiment on the Recovering pf Sodium Phosphate from Incinerated Ash of Sewage Sludge." In Proceedings of the 12th Annual Conference of the Japan Society of Waste Management Expert, 280-2.

[7] Takahashi, M., Takemoto, Y. and Oonishi, K. 2013. "Recovery of Aluminum Phosphate Using Magnesium hydroxide from Incinerated Ash of Sewage Sludge." Journal of Material Science and Engineering A 3 (10): 
710-3.

[8] Sato, K., Takahashi, M., Onari, Y., Kato, S. and Enjyoji, H. 2004. "A Technique for Recovering Sodium Phosphate from Sewage Sludge by Hydrothermal Synthesis.” Transactions of Materials Research Society of Japan 29 (5): 2021-4.

[9] Takahashi, M., Kato, S., Iwasaki S. and Miura, K. 2001. "Technology for Recovering Phosphorus Salt and Zeolite from Incinerated Ash of Sewage Treatment Sludge.” Journal of Advanced Science 13 (3) 163-6.
[10] Tezuka, M., Asano, T., Toba, A., Cobayasi, Y., Isioka, M. and Taziri, K. et al. 1995. "Treatment of Waste, -Solution with Freeze Dilution.” Annual Report of Hokkaido Research Organization Industrial research Institute, 294: 83-90.

[11] Tosoh Corporation. About Zeolite. Accessed Oct. 20, 2016. http://www.tosoh.co.jp/zeolite/about/index.html.

[12] Wikipedia, Phosphoric acid, https://ja.wikipedia.org/wiki/\%E3\%83\%AA\%E3\%83\%B 3\%E9\%85\%B8. Accessed Oct. 4, 2016. 